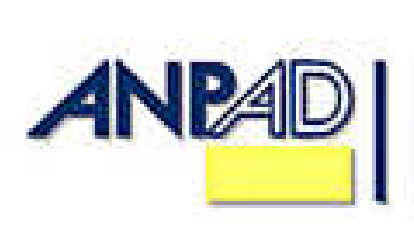

Disponível em

http://www.anpad.org.br/rac

RAC, Curitiba, v. 14, n. 1, art. 5,

pp. 80-99, Jan./Fev. 2010

\title{
Medindo a Imagem do Destino Turístico: uma Pesquisa Baseada na Teoria de Resposta ao Item
}

Measuring the Tourism Destination Image: a Survey Based on the Item Response Theory

Amalia Raquel Pérez-Nebra* Doutoranda em Psicologia Social, Organizacional e do Trabalho pela UnB. Professora do UniCEUB, Brasília/DF, Brasil.

Cláudio V. Torres Ph.D. em Psicologia pela California School of Professional Psychology, Estados Unidos. Professor da UnB - IP, Brasília/DF, Brasil.

* Endereço: Amalia Raquel Pérez-Nebra

SQN 406, Bloco J, apto. 103, Brasilia/DF, 70847-100. E-mail: amalia@unb.br

Copyright (C 2010 RAC. Todos os direitos, inclusive de tradução, são reservados. É permitido citar parte de artigos sem autorização prévia desde que seja identificada a fonte. 


\title{
RESUMO
}

O potencial turístico do Brasil é reconhecido por diversos segmentos, e sabe-se de sua pouca representatividade no cenário internacional. Objetivou-se a construção e validação de um Instrumento de Imagem do Destino Turístico, e posterior comparação dos turistas reais e potenciais, além de uma revisão sobre o conceito de imagem do destino. Para a pesquisa se construiu um sítio eletrônico em quatro idiomas e enviaram-se e-mails nos mesmos idiomas. A pesquisa foi respondida por 658 pessoas, de 66 diferentes países. A média de idade foi de 33,2 anos $(\mathrm{dp}=11,5), 58,7 \%$ eram do sexo feminino, 53,9\% eram solteiros, mais de $80 \%$ concluíram o terceiro grau, a maioria já fez viagem internacional (90,8\%), mas poucos vieram ao Brasil $(26,8 \%)$. O tratamento dos dados foi por meio de análise fatorial e análise de resposta ao item, além da diferença entre grupos. Os resultados ofereceram subsídios para alcançar o objetivo de construir e validar um Instrumento de Imagem do Destino. Foram encontrados cinco fatores: 1. Cenário específico, 2. Cultura local, 3. Luxo e conforto, 4. Infra-estrutura e segurança, e 5. Recreação e entretenimento. O segundo objetivo foi alcançado. Comparando os grupos, dois fatores apresentaram diferença entre turistas potenciais e reais. Aplicações e impactos são sugeridos ao longo do trabalho.

Palavras-chave: turismo; imagem do destino; validação; medida.

\begin{abstract}
Potential Tourism in Brazil is recognized by some segments. Yet it is known to represent little in the international scenario. The purpose of this study is to construct and validate a Tourism Destination Image Scale for comparison between real tourists and potential tourists, as well as the literature review of the destination image concept. For this study, an electronic site in four different languages was used, with e-mails being written and sent in the same four languages. 658 from 66 different countries responded. The sample was made up of females $(58.7 \%)$, singles $(53.9 \%)$, with an average age of $33.2(\mathrm{SD}=11.5)$ years. More than $80 \%$ had completed a bachelor's degree, the majority travelled to international locations (90.8\%), but few travelled to Brazil $(26.8 \%)$. Factor analysis, Item Response Theory and Group Differences were conducted. The results validated the Destination Image Scale. Five factors were found in this study: 1. Specific scenario, 2. Local culture, 3. Luxury and comfort, 4. Infra-structure and security, and 5. Recreation and entertainment. The second aim was achieved. The comparison between potential and real tourists shows differences in two factors. Applications and impacts were suggested in the work.
\end{abstract}

Key words: tourism; destination image; validation; measurement. 


\section{INTRODUÇÃO}

O turismo é o maior dos movimentos migratórios da história da humanidade, caracteriza-se por sua taxa de crescimento constante (Organização Mundial de Turismo [OMT], 2001; Ruschmann, 1990), já foi apontado como o primeiro setor da economia mundial (Ansarah, 2002) e passou a ser assunto constante em diversos meios (Bignami, 2002). Uma das características mais marcantes do turismo é tratar de um serviço, cujo processo é essencialmente comercial e, como tal, simbólico e intangível, e cujo resíduo é uma experiência vivencial (Barretto, 2000; Bignami, 2002; Paiva, 1995; Ruschmann, 1990). Outra de suas características é a heterogeneidade da demanda ao receptivo turístico, fazendo com que as imagens dos destinos sejam altamente diversificadas. Tal fato torna sua apreciação e percepção de vivência sujeitas às mais diversas interpretações (Ruschmann, 1990). O turismo pode, portanto, ser facilmente dividido em segmentos de interesse ou exploração, por investidores e pesquisadores. Esta amplitude de possibilidades apresenta aspectos positivos e negativos: se por um lado os horizontes de análise se ampliam, por outro dificultam sua definição e delimitação do campo de estudo.

Este estudo é continuação da proposta de pesquisa apresentada por Pérez-Nebra e Torres (2002a) na área de turismo sobre a ótica do comportamento do consumidor. Os autores propuseram um modelo de estudos sobre o turismo de amplitude nacional e, entre eles, a construção e validação de uma escala para imagem do turismo no Brasil, como forma de mensuração e validação desse modelo posteriormente. Para chegar a este objetivo, o presente trabalho responde à primeira necessidade, a da construção e validação dessa escala, bem como um percurso pela literatura pertinente.

\section{Turismo}

A gestão de turismo em âmbito nacional é fundamentalmente pública, uma vez que as organizações privadas que prestam este serviço são compostas, na sua maioria por micro, pequenas e médias empresas (Paiva, 1995; Petrocchi, 2001). Este padrão de funcionamento se repete em diversas parte do mundo (Paiva, 1995; Petrocchi, 2001; Trigo, 2000). Desta maneira, o Estado é a parte mais indicada para investir somas em pesquisas, marketing internacional, infra-estrutura, entre outros. Todavia, no Brasil, há uma característica de falta de competitividade e não-organização do setor para pesquisa.

Por outro lado, alguns dados ilustram o impacto social e econômico desse setor e a necessidade de pesquisas para a profissionalização da área. Em 1996 o turismo representou 10,7\% do PIB mundial, em 1999 foi 8\% (OMT, 1999, 2001). O turismo empregou, somados os diversos países que compõem a OMT, 260 milhões de pessoas, um faturamento de 3,4 trilhões de dólares e 655 bilhões de dólares em impostos (Beni, 2001).

Além de dar suporte à idéia do seu impacto social e econômico, esses números demonstram também que o turismo, mais do que gerador de renda, é gerador de trabalho (Beni, 2001). No caso brasileiro este argumento é fundamental, quando se considera a taxa de desemprego nacional em torno de $10 \%$ (Instituto Brasileiro de Geografia e Estatística [IBGE], 2007). Vale a ressalva de que a dependência econômica ao turismo torna-a débil (Paiva, 1995) e talvez inviável (Petrocchi, 2001). Portanto, a proposta não é solucionadora dos males nacionais, mas uma profissionalização do setor. Para tal, é preciso conhecer como o turista imagina e percebe o turismo.

\section{Dimensões do Turismo}

As dimensões do serviço turístico, do ponto de vista do consumidor, são as atrações do núcleo receptor, as vias e os meios de acesso, e as facilidades que são oferecidas ao turista (OMT, 2003; Ruschmann, 1990). A OMT (2003) sugere dez dimensões básicas de turismo, as quais foram corroboradas em diferentes níveis por pesquisas empíricas e por teóricos da área, que serão apontados adiante. Segundo esta organização, as dimensões que compõem o turismo são: 1. Serviço de 
alojamento; 2. Provisão de alimentação e bebidas; 3. Transporte de passageiros; 4. Agência de viagem, operadoras e guias de turismo; 5. Serviços culturais; 6. Recreativos e lazer; 7. Comércio; 8. Cenário; 9. Cordialidade da população local; 10. Diversos. A OMT descreve como Diversos o serviço financeiro, como, por exemplo, o câmbio do dinheiro (troca), a possibilidade de retirada em caixas eletrônicos, o valor financeiro do câmbio, facilidade de compra, de aluguel de carros, de casa ou apartamento de veraneio, bicicleta ou qualquer outro bem necessário durante o tempo de estada no país. Esta dimensão está ligada basicamente à logística de suporte do viajante. Como mencionado, tais dimensões têm sido identificadas em pesquisas empíricas relacionadas à satisfação, expectativa e imagem do turista com respeito ao destino turístico (Allen, 1997; Amend, Silva, Niefer, \& Martins, 2002; Bignami, 2002; Day, Skidmore, \& Koller, 2002; Joppe, Martin, \& Waalen, 2001; Kahle, 1995; Pérez-Nebra \& Torres, 2002b; Spotts, Kim, Carr, \& Holecek, 1998). Vale notar que alguns desses pesquisadores identificaram entre uma e cinco dimensões do turismo em suas pesquisas empíricas, mas nunca as dez dimensões em conjunto foram descritas e testadas em uma mesma pesquisa. Ela é apenas descrita teoricamente pela OMT. De qualquer forma, essas dimensões compõem a representação mental daquele destino, carregada de avaliações que estão ligadas à história passada e de aprendizagens do indivíduo. Em outras palavras, elas compõem a imagem do destino turístico.

O instrumento construído para esta pesquisa sobre imagem considerou a proposta dessas 10 dimensões para que houvesse o conhecimento de qual delas, e em que magnitude, são relevantes para o turismo nacional. Além disso, essa decisão contribui empiricamente para área por testar, em uma mesma pesquisa, todas as dimensões com um survey. A seguir será apresentado uma breve revisão da imagem do destino turístico.

\section{IMAGEM DO DESTINO}

O turismo é um bem de consumo predominantemente abstrato (intangível) e é apresentado aos consumidores potenciais por meio de descrições, narrações, mídia e fotos. Assim, o que induz o cliente à sua compra são as promessas de satisfação que o destino pode oferecer (Bignami, 2002; Day et al., 2002; Paiva, 1995; Ruschmann, 1990; Spotts et al., 1998) e a motivação que o turista tenha para essa viagem (Swarbrooke \& Horner, 2002). Logo, a imagem do destino é uma característica determinante no processo de decisão de compra do consumidor turístico (Bignami, 2002; Leal, 2004; Spotts et al., 1998). A Teoria da Imagem (Alexander, Brewer, \& Livingston, 2005), mais geral que de imagem do destino, hipotetiza, ainda, que estereótipos inter-étnicos específicos derivam de padrões de competição percebida, diferença de poder, e status cultural de cada grupo. Portanto, a nação a que o indivíduo pertence impacta na avaliação que ele realiza do destino.

O turista, antes de viajar, faz previsões das experiências que pretende ter. Estas estão fundamentadas nas emoções que o destino evoca na sua memória, por comentários de amigos, pela leitura da folheteria, anúncios publicitários etc. Sua decisão basear-se-á na imagem que ele valoriza e espera encontrar (Crompton, 1979). Sendo assim, a escolha do destino vai depender de imagens favoráveis que o consumidor tenha do lugar (Echtner \& Ritchie, 1991). Caso contrário, o consumo do turismo simplesmente não ocorre (Bignami, 2002; Leisen, 2001). Na tentativa de fazer predições e conseguir explicações para diversos fenômenos do comportamento do consumidor, vários modelos trataram de delinear e explicar o comportamento do consumidor de turismo (Jacoby, Hoyer, \& Brief, 1992; Simonson, Carmon, Dhar, Drolet, \& Nowlis, 2001; Swarbrooke \& Horner, 2002), entre eles a formação da imagem. A maioria dos modelos pode ser resumida em três estágios, com diferentes níveis de descrições e nominações para cada um deles: pré-compra, compra e pós-compra (e.g., Jacoby et al., 1992; Pérez-Nebra \& Torres, 2002a; Swarbrooke \& Horner, 2002).

Pressupõe-se que o turismo, para a maior parte das pessoas, seja uma atividade de alto envolvimento, por ser relativo às férias das pessoas (momento de prazer e descanso do trabalho), planejado (em sua maioria) com altos custos financeiro, cognitivo e psicológico. Ainda, para muitos, é um serviço com alto significado simbólico (e.g., status social, lua-de-mel, aprovação social) (Allen, 
1997). No momento desta suposta busca de informações é que ocorreria a formação da imagem da marca (ou, imagem do destino). Nesse caso, da imagem da marca de destino turístico (Echtner \& Ritchie, 1991). Vale ressaltar ainda que existem informações que advêm não apenas da procura ativa, mas de outros meios de comunicação que são assimilados pelo sujeito.

Nessa busca por informações externas, caso alguma alternativa de marca apresente empecilhos ou dificuldades em sua procura, sabe-se que ela pode ser ignorada em favor de marcas com informações de acesso mais facilitados (Jacoby et al., 1992). Como exemplo, pode-se ilustrar que há milhares de possibilidades de viagem para o exterior. Porém, a maioria dos consumidores escolhe o mesmo destino turístico, Paris (OMT, 2000, 2003), provavelmente porque o custo-benefício de aquisição de informação e a percepção de baixo risco compensem o fato de não buscarem mais informações sobre outros locais.

Posteriormente à busca de informações, o consumidor trata de consolidar e avaliar tais informações que procurou. Assim, antes de qualquer viagem, o turista prevê experiências que terá com o destino, evocando emoções positivas, e a escolha desta viagem para férias vai depender largamente do favoritismo desta imagem de destino (Leisen, 2001). Os turistas escolherão, dentre suas possibilidades, o destino compatível com as imagens mais favoráveis (Crompton, 1979; Echtner \& Ritchie, 1991; Hunt, 1975).

Uma destinação turística pode ser definida como a região para onde os turistas se deslocam durante suas viagens (Leal, 2002). Já a definição da imagem dessa destinação turística é um conceito que mudou desde os anos 1970 (Hunt, 1975). Até esta data, o construto imagem do destino se resumia nas impressões de um lugar, organizadas e que poderiam pertencer a potenciais ou a reais turistas. Crompton (1979) agregou a este construto crenças e idéias, dando uma característica subjetiva à definição. A partir de então, características psicológicas começaram a ser incluídas neste conceito. Segundo ele, a imagem pode ser definida como a "soma de crenças, idéias e impressões que uma pessoa possui de um destino" (p. 18) e pode equivaler em variação ao número de sujeitos perguntados.

A literatura de Imagem do Destino descreve diversos métodos possíveis de mensuração, dentre eles utilizando imagens pictóricas, descrições qualitativas, análise documental (e.g. Bignami, 2002; Crompton, 1979; Echtner \& Ritchie, 1991; Mariani, 2002). Por outro lado, para uma avaliação padronizada, generalizável e comparável, objetivo deste trabalho, já que abrangia vários países e diferentes públicos, optou-se por uma mensuração via questionário estruturado. Portanto, torna-se premente a necessidade de criar um instrumento validado psicometricamente, para confirmar ou refutar tais afirmações.

A imagem representa o destino mental do viajante e lhe dá um pré-teste do mesmo destino (Echtner \& Ritchie, 1991). Isto determina as possibilidades de escolha de destino. Assim, na presente pesquisa, a imagem do destino foi considerada como representação mental, carregada de afeto e cognição sobre um destino turístico. Essa definição torna a imagem do destino um conceito pré-atitudinal, composto por dois dos três elementos da atitude. Como o terceiro elemento, comportamental, de experiência com o destino, ainda não foi apontado pela literatura como parte do conceito e deverá ser testado (Fishbein \& Ajzen, 1975; Rodrigues, Assmar, \& Jablonski, 1999). Desta maneira, o segundo objetivo do trabalho é comparar a imagem de turistas que vieram ao Brasil (turistas reais) com os que não vieram (turistas potenciais); caso haja diferença entre eles, pode-se pressupor a existência de um componente conativo da atitude.

\section{Pesquisas sobre o Brasil}

Até a presente data, na América do Sul, parte das pesquisas na área de turismo é, sobretudo, financiada por empresas privadas, e está destinada a estudar o mercado para benefício dessas empresas. Outra parte vem de estudos com financiamento variado e pouco sistematizado. Os governos apenas se responsabilizam por alguns estudos estatísticos que, além de apresentarem limitações ligadas à confiabilidade, objetivam apenas um registro quantitativo descritivo dos turistas que cruzam 
suas fronteiras, com pesquisas exclusivamente intuitivas (Barretto, 2000; Laverie \& Murph, 1993). Os setores do governo nacional necessitam de maior aprofundamento com base em pesquisa científica, espelhando-se em agências reguladoras estrangeiras, que utilizam, há muito tempo, o instrumental do comportamento do consumidor e da psicologia em políticas públicas (Barretto, 2000; Joppe et al., 2001; Laverie \& Murph, 1993; Rezende-Parker, Morrison, \& Ismail, 2003).

Ainda que a importância do tópico seja inquestionável, a quantidade de investigações sobre imagem no Brasil é mínima (Leal, 2002). Na revisão de literatura realizada foram encontrados poucos estudos sobre a imagem do destino Brasil. Um dos estudos foi o de Bignami (2002). Em sua pesquisa, ela categorizou diversos discursos em distintos meios de comunicação e encontrou cinco categorias de atratividade turística. Estas são: (1) O Brasil paraíso; (2) O lugar de sexo fácil; (3) O Brasil brasileiro; (4) País do Carnaval; e finalmente (5) O lugar do exótico e do místico. Segundo esta autora, a imagem turística do Brasil no exterior é altamente estereotipada, centrada em alguns poucos eventos culturais nacionais e em determinadas características que qualificam o povo brasileiro.

A pesquisa realizada por Leal (2004) combinou técnicas de análise quantitativa e qualitativa. Sua pesquisa foi realizada com 140 estudantes australianos com questionário tipo lápis-e-papel. As respostas de todas as questões abertas apresentaram a cultura como característica central do turismo nacional. As questões integram-se ao dizer que o Brasil está relacionado ao meio-ambiente. Os dados quantitativos foram captados por itens, resultando em seis fatores. Os títulos dados foram: (1) Reputação, atratividades e locais; (2) Infra-estrutura e facilidade; (3) Ambiente natural, oportunidade de ganhar conhecimento e para aventura; (4) Bons preços, entretenimento e festivais; (5) Gastronomia, restaurantes e acomodação; (6) Cidades desenvolvidas e atrativas.

Rezende-Parker et al. (2003) obtiveram resposta de 246 participantes estadunidenses, sendo o questionário aplicado pela Internet. As respostas foram muito similares às encontradas por Leal (2004); todas as questões tiveram respostas relacionadas a meio ambiente e festividades, além da falta de segurança pessoal. Os fatores encontrados foram: (1) atrações naturais e interesse; (2) segurança e conforto; (3) comparações culturais; (4) facilidades e informações; (5) atmosfera de férias e exótico; (6) condição econômica e social; (7) transporte, e finalmente (8) aventura e aprendizagem.

Estes trabalhos apresentaram alguns fatores e itens diferentes entre si. O primeiro trabalho (Leal, 2004) apresentou 6 fatores; o segundo (Rezende-Parker et al., 2003) 8 fatores. Alguns dos fatores encontrados nos dois estudos foram relativamente similares (natureza-aventura-aprendizagem e infraestrutura e facilidades). Não obstante, outros fatores são muito distintos (como é o caso de reputação e atratividades locais, bons preços, condição econômica e social, transportes, segurança e conforto, entre outros). Infelizmente não há dado que descreva a elaboração da redação dos itens do primeiro estudo nem da composição dos itens nos fatores. Além de haver diferença entre o número de itens que compõem aqueles fatores similares. Tais observações, aliadas à importância do tema, justificam a construção de um instrumento psicometricamente válido e confiável, e que possa servir de base para pesquisas no país. Esse objetivo de pesquisa, além da testagem da existência do componente conativo da imagem de destino, foram buscados por meio do método descrito a seguir.

\section{MÉTODO}

\section{Participantes}

Participaram deste estudo 658 respondentes, a partir de amostra inicial de 690 pessoas. O total de casos válidos (preenchimento acima de $95 \%$ do questionário) foi igual a 658 , os quais eram usuários de e-mail e Internet de 66 países diferentes. Aqueles que mais responderam ao questionário foram estadunidenses $(22,5 \%)$, seguidos dos ingleses $(7,1)$, peruanos $(6,8)$, canadenses $(5,6 \%)$ e alemães $(5,0 \%)$; os demais países tiveram representações abaixo de 5\%. O idioma de resposta do instrumento mais escolhido foi o inglês $(58,8 \%)$, seguido de espanhol (29,3\%). Do total de respondentes, $58,7 \%$ 
eram do sexo feminino, com média de idade de 33,2 anos ( $\mathrm{dp}=11,5)$, mais de $80 \%$ já tinham concluído o terceiro grau. A maioria era solteiro (53,9\%), sem filhos $(67,1 \%)$. A média de renda era de $56.784,13$ dólares americanos ao ano $(\mathrm{dp}=150.300,7)$, a maioria já fizera viagem internacional $(90,8 \%)$, mas poucos vieram ao Brasil $(26,8 \%)$.

\section{Instrumento}

O instrumento foi construído com o objetivo de mensurar a imagem que turistas fazem a respeito do destino turístico Brasil e era composto de duas partes: a primeira sobre imagem, a segunda de dados pessoais.

O instrumento final foi composto de 69 itens com amplitude de escala de avaliação de 5 pontos de concordância. Os itens foram construídos com fundamento na literatura pertinente e agrupados nos 10 componentes do turismo. Foi realizada com uma validação de juízes, com uma amostra composta por 6 pesquisadores do Grupo Consuma - Pesquisas em Comportamento do Consumidor (www.consuma.unb.br), com critério de concordância de itens de $80 \%$, conforme sugerido pela literatura (Pasquali, 1999). Quando algum item apresentava concordância mediana, entre $60 \%$ e 80\%, optou-se pela reformulação dele. Quando havia concordância inferior a 60\%, este era eliminado. Esses parâmetros permitiram eliminar três e reformular dezesseis itens.

Após a análise de juízes, foi realizada a aleatoriedade dos itens por meio do software Excel. Com o instrumento em versão final em português, as traduções e re-traduções foram realizadas com nativos para o espanhol, inglês e francês e uma análise semântica de cada idioma foi realizada, com exceção do francês (Brislin, 1980; Brislin, Lonner, \& Thorndike, 1973).

\section{Procedimento}

A coleta de dados para este estudo ocorreu entre 22 de março e 22 de maio de 2004 . Foram enviadas cartas eletrônicas para 452 pessoas, com a solicitação de que estas enviassem para o maior número possível de estrangeiros não residentes no Brasil, criando um efeito de bola de neve que objetivou a validação e comparação no maior número de países possível. A taxa de resposta foi de 1,45 sujeitos por e-mail enviado.

Houve dificuldades com a interface ASP no provedor gratuito, que aceitava apenas 500 acessos ASP e no programa Access 97 e 2000, o qual aceita menos de 250 respostas no banco de dados. Por isso, alguns sujeitos foram perdidos com esses entraves, que obrigou a página ficar entre 48 e 72 horas fora do ar.

\section{Análise de Dados}

Foram considerados válidos os questionários em que os indivíduos haviam preenchido pelo menos 95\% dos itens de Imagem do Destino (máximo aceito de 3 respostas em branco), e que não fossem residentes no Brasil.

Foram feitas análises de fatorabilidade, como medida de adequação da amostra de Kaiser Meyer Olkin [KMO], valor do determinante, do eigenvalor e da variância explicada. De posse dos dados, análises de fatoração do eixo principal (PAF) com rotação oblimin foram realizadas com o instrumento (como sugerido por Pasquali, 2006). Após a análise de fatoração foi realizada a análise de confiabilidade do instrumento. A análise fatorial foi escolhida pela sua capacidade de agrupar variáveis que os participantes descrevem ou avaliam de maneira similar. Se avalia similar, é porque é percebido de maneira similar; sendo assim, podem ser agrupados em uma mesma categoria. Esta técnica estatística é poderosa para auxiliar pesquisadores, governo, agências e organizações a entenderem como os participantes avaliam seus produtos ou serviços. 
A última análise do processo de validação foi de Teoria de Resposta ao Item [TRI], com o pacote estatístico PARSCALE, único pacote de cálculo de TRI para escalas politômicas, utilizando o modelo de dois parâmetros, ou seja, a dificuldade e discriminação de cada item (Muraki \& Bock, 1997; Pasquali, 2004). Utilizou-se o Modelo de Atributo Parcial logístico, optando por distribuição lognormal tanto para os parâmetros de dificuldade como discriminação com método de Estimação de Probabilidade Máxima (Maximum Likelihood Estimantion [MLE]).

Vale a pena notar que são dois os objetivos desta análise. Um deles é para descrever o quanto um item, dentro de um mesmo fator, discrimina a avaliação realizada pelos diferentes participantes, ou seja, se um item é avaliado da mesma maneira por todo o mundo, ele torna-se pouco útil, já que passa a ser uma variável que não varia entre os diferentes grupos de pessoas; é útil apenas para diagnóstico. $\mathrm{O}$ outro objetivo é descrever a facilidade e dificuldade que o participante tem em endossar o item apresentado a ele. Como exemplo, pode-se dizer que, em uma escala de satisfação, dizer que o atendente não foi antipático ou dizer que o atendente foi extremamente solícito são itens que podem fazer a média ficar superfaturada ou parecer pior do que é, em função de como o item foi construído. Um dos erros que a análise TRI pode evitar é o Efeito Halo (e.g. Wirtz \& Bateson, 1995).

Foram realizadas ainda análises descritivas e de comparação entre turistas reais e potenciais, por meio de uma análise One-way ANOVA. Não foi possível realizar análises entre os países, já que o número de participantes é muito díspar ${ }^{(1)}$.

\section{RESULTADOS}

Esta sessão é dividida em duas partes. A primeira delas apresenta os resultados obtidos no estudo de validação do instrumento de Imagem do Destino Turístico, a segunda de comparação entre a imagem dos turistas potenciais e dos reais.

\section{Análise de Validade do Instrumento de Imagem do Destino Turístico}

A Tabela 1 apresenta os resultados da análise de componentes principais de fatorabilidade para o instrumento de Imagem. Esta análise preliminar verificou que a matriz das intercorrelações era fatorável, porque apresentou suficiente covariância que permitisse a busca de fatores. $\mathrm{O}$ coeficiente KMO, que indica tal fato, foi de 0,88 que pode ser considerado meritório, segundo Pasquali (2006).

A análise de componentes principais apresentou três dados relevantes: (1) o determinante de 2,63.1012 indica a presença de um número reduzido de fatores; (2) a análise dos eigenvalores com valores iguais ou acima de 2, e (3) o fator ter apresentado uma variância explicada de, pelo menos, $3 \%$. A análise fatorial pelo método de Fatoração pelo Eixo Principal confirmou a estrutura apontada pela análise de componentes principais. A estrutura foi pentafatorial e explicou pouco mais de $34 \%$ da variância de respostas, convergindo em 22 interações para o arranjo dos fatores. Apenas uma variável foi alocada em outro fator, que não o demonstrado pela análise fatorial. Esta escolha foi feita com base na relação teórica e por apresentar carga fatorial aceitável $(0,31)$ (foi alocada no Fator 4 - Bonitas áreas de camping).

A análise também apresentou uma tabela de correlação entre os fatores, de maneira a verificar a presença de um fator mais geral de segunda ordem. $\mathrm{O}$ resultado demonstrou que as correlações não poderiam ser consideradas como altas (abaixo ou igual a 0,35). Portanto, não seria indicada uma extração com menor número de fatores. A análise de estimativa de precisão dos fatores foi realizada por meio da análise de Alfa de Cronbach. 
Tabela 1

Verificação Empírica da Consistência e Independência dos Fatores para N de Casos = 658

\begin{tabular}{lccccc}
\cline { 2 - 6 } & \multicolumn{5}{c}{ Fator } \\
\cline { 2 - 6 } Variável & 1 & 2 & 3 & 4 & 5 \\
Número de itens por fator & 12 & 13 & 9 & 8 & 11 \\
Alfa de Cronbach & 0,80 & 0,84 & 0,66 & 0,74 & 0,73 \\
Eigenvalor & 11,17 & 4,94 & 3,20 & 2,35 & 2,07 \\
\% de variância explicada & 16,19 & 7,16 & 4,64 & 3,40 & 3,00 \\
\hline
\end{tabular}

Como pode ser observado na Tabela 1, dos cinco fatores apresentados, apenas um apresenta índice de precisão abaixo de 0,7 . Entretanto, pode ser considerado um fator promissor, porque a diferença para um índice de precisão considerado adequado é pequena (de 0,03$)$ e o fator, como será tratado com mais detalhes na discussão, não foi apontado pela literatura de imagem do destino, o que também defende sua permanência como um fator. A interpretação dos itens sugeriu as seguintes denominações: (1) Cenário específico do país Brasil como destino turístico, (2) Infra-estrutura turística, (3) Luxo e conforto, (4) Cultura local e (5) finalmente Recreação e entretenimento.

Para o cálculo TRI foram considerados cinco fatores, mesmo sabendo que em um deles existem algumas restrições de precisão. A Tabela 2 apresenta os resultados da análise dos itens; nela aparecem as seguintes informações sobre cada item: (1) o item como ele foi apresentado no questionário original daquilo que o participante imaginava que encontraria no Brasil (2) fator ao qual ele pertence (3) item na ordem original (4) índice de dificuldade do item (parâmetro $b$ ), (5) distribuição dos itens por Faixa de dificuldade, (6) índice de discriminação do item (parâmetro $a$ ), (7) carga fatorial, (8) nova ordem proposta para o instrumento. Esta análise aponta uma nova configuração para os itens do Instrumento, já que o sujeito deve sempre responder em uma ordem crescente de dificuldade (Pasquali, 2004). 
Tabela 2

Estrutura Empírica e Propriedades Psicométricas do Instrumento de Imagem do Destino Turístico para N de Casos = 658 para a Carga e N de Casos = 622 para TRI

\section{Variável}

Lindas paisagens

Lindas praias

Florestas tropicais

Coisas novas, diferentes e interessantes

Um clima bom

Excelentes opções de lugares para nadar

Frutas diferentes

Uma variedade de lugares cênicos nas viagens

Comida exótica

Excelentes lugares para dançar

Uma população hospitaleira

Variedade de entretenimento

Boas informações turísticas no país

Fáceis informações nas agências de viagem do destino

Com freqüência hotéis típicos

Facilmente serviços de informação no destino

Facilidade para um táxi

Um serviço de transporte local eficiente

Facilidade na comunicação com a população local

Sinais fáceis no país (direções e instruções)

Um lugar limpo

Um destino seguro para o turista

Um câmbio muito flutuante

Um ambiente com fama ruim de segurança publica

Uma grande distância para que eu chegue lá

Um lugar não comercial (eu não encontraria outros turistas)

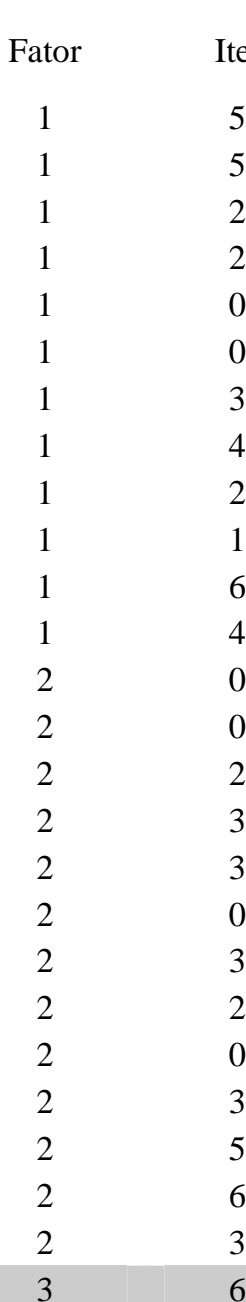

\begin{tabular}{c} 
Dificuldade \\
-2.838 \\
-2.727 \\
-2.630 \\
-2.551 \\
-2.289 \\
-2.192 \\
-2.123 \\
-2.084 \\
-2.076 \\
-2.038 \\
-1.811 \\
-1.609 \\
-1.269 \\
-1.021 \\
-0.886 \\
-0.800 \\
-0.722 \\
-0.402 \\
-0.187 \\
-0.144 \\
-0.052 \\
0.024 \\
0.293 \\
0.858 \\
2.291 \\
-1.556 \\
\hline
\end{tabular}

Faixa de

Dificuldade

I

I

I

I

I

I

I

I

I

I

I

II

II

II

II

II
III

III

III

III

III

IV

V

Discriminação
1.138
1.090
0.517
0.628
0,403
0,335
0.641
0.574
0.579
0.452
0.488
0.740
0.701
0.727
0.559
1.017
0.516
0.616
0.287
0.637
0.650
0.451
0.442
0.317
0.259
0.133

\begin{tabular}{|c|c|}
\hline $\begin{array}{l}\text { Carga } \\
\text { fatorial }\end{array}$ & $\begin{array}{l}\text { Nova } \\
\text { ordem }\end{array}$ \\
\hline ,688 & 1 \\
\hline 699 & 2 \\
\hline ,403 & 3 \\
\hline ,456 & 4 \\
\hline ,488 & 6 \\
\hline, 337 & 7 \\
\hline ,463 & 8 \\
\hline ,446 & 9 \\
\hline ,331 & 10 \\
\hline ,332 & 11 \\
\hline ,417 & 17 \\
\hline ,385 & 21 \\
\hline,- 549 & 26 \\
\hline,- 529 & 29 \\
\hline,- 336 & 31 \\
\hline,- 603 & 32 \\
\hline,- 359 & 35 \\
\hline,- 618 & 38 \\
\hline,- 369 & 40 \\
\hline,- 608 & 41 \\
\hline,- 642 & 42 \\
\hline,- 695 & 43 \\
\hline, 341 & 44 \\
\hline, 583 & 46 \\
\hline ,366 & 51 \\
\hline ,339 & excluído \\
\hline
\end{tabular}

Continua 


\section{Tabela 2 (continuação)}

Variável

Boas opções de hotéis cinco estrelas e resorts

Uma variedade de produtos para compra

Ampla infra-estrutura de gastronomia e culinária

Opções de restaurantes com cozinha internacional

Ampla infra-estrutura de hotéis

Um custo de vida baixo

Um câmbio favorável para mim

Opções para fazer uma viagem econômica

Como aprender sobre a cultura local

Uma variedade de lugares históricos

Produtos manufaturados para comprar à vontade

Uma variada arquitetura

Como aprender sobre cultura africana

Um destino que oferece facilidades para mochileiros

Bons museus no destino

Uma variedade de museus

Carnaval que é uma festa típica da qual eu participaria

Comida típica

Celebrações típicas

Várias festas típicas no destino

Boas facilidades de esportes nas praias

Pessoas apaixonadas no destino turístico

Bonitas áreas de camping

Facilidade para pescaria.

Áreas de corrida no destino

Parques temáticos para ir

Usos e costumes parecidos ao do meu país

\begin{tabular}{|c|c|c|c|c|c|c|}
\hline Fator & Item & Dificuldade & $\begin{array}{c}\text { Faixa de } \\
\text { Dificuldade }\end{array}$ & Discriminação & $\begin{array}{l}\text { Carga } \\
\text { fatorial }\end{array}$ & $\begin{array}{l}\text { Nova } \\
\text { ordem }\end{array}$ \\
\hline 3 & 27 & -2.022 & I & 0.533 &,- 411 & 12 \\
\hline 3 & 44 & -1.875 & I & 0.629 &,- 330 & 14 \\
\hline 3 & 67 & -1.816 & I & 0.733 &,- 335 & 16 \\
\hline 3 & 66 & -1.780 & I & 0.853 &,- 400 & 18 \\
\hline 3 & 53 & -1.471 & I & 0.792 &,- 378 & 23 \\
\hline 3 & 22 & 1.079 & IV & 0.244 & ,427 & 47 \\
\hline 3 & 17 & 1.148 & IV & 0.240 & ,345 & 48 \\
\hline 3 & 06 & 1.272 & IV & 0.237 & ,399 & 49 \\
\hline 4 & 61 & -1.959 & I & 0.576 & ,423 & 13 \\
\hline 4 & 56 & -1.719 & I & 0.488 &, 525 & 19 \\
\hline 4 & 36 & -1.490 & I & 0.562 & ,441 & 22 \\
\hline 4 & 09 & -1.349 & I & 0.435 & ,365 & 24 \\
\hline 4 & 58 & -1.078 & II & 0.350 & ,475 & 27 \\
\hline 4 & 57 & -0.943 & II & 0.432 & ,435 & 30 \\
\hline 4 & 25 & -0.574 & II & 0.782 & ,614 & 36 \\
\hline 4 & 52 & -0.493 & III & 0.882 & ,658 & 37 \\
\hline 5 & 08 & -2.339 & I & 0.165 & ,328 & excluído \\
\hline 5 & 26 & -2.347 & I & 0.311 & ,331 & 5 \\
\hline 5 & 41 & -1.865 & I & 0.681 & ,388 & 15 \\
\hline 5 & 59 & -1.656 & I & 0.608 & ,416 & 20 \\
\hline 5 & 18 & -1.348 & I & 0.468 &, 451 & 25 \\
\hline 5 & 33 & -1.029 & II & 0.464 & ,471 & 28 \\
\hline 5 & 60 & -0.761 & II & 0.435 & ,311 & 33 \\
\hline 5 & 34 & -0.740 & II & 0.668 & ,456 & 34 \\
\hline 5 & 40 & -0.402 & III & 0.540 & ,426 & 39 \\
\hline 5 & 69 & 0.316 & III & 0.416 & ,391 & 45 \\
\hline 5 & 10 & 2.160 & V & 0.184 & ,362 & 50 \\
\hline
\end{tabular}

Nota. Fonte: elaborado pelos autores. 
Com base nesta análise, optou-se por manter o item 'Bonitas áreas de Camping', já que ele é um dos três itens do Fator 5 (Recreação e entretenimento) que apresenta dificuldade na Faixa II e discriminação acima de 0,40 . Pode-se perceber que alguns itens apresentam índices de dificuldades baixos, ou seja, na Faixa I; e índices de discriminação precário, abaixo de 0,2. Estes itens com discriminação abaixo de 0,2 são apontados em cinza e foram excluídos. A seguir serão apresentados resultados sumariados dos fatores (Tabela 3) para avaliação global dos fatores:

Tabela 3

\section{Sumário Estatístico dos Parâmetros do Fator para N de casos = 622}

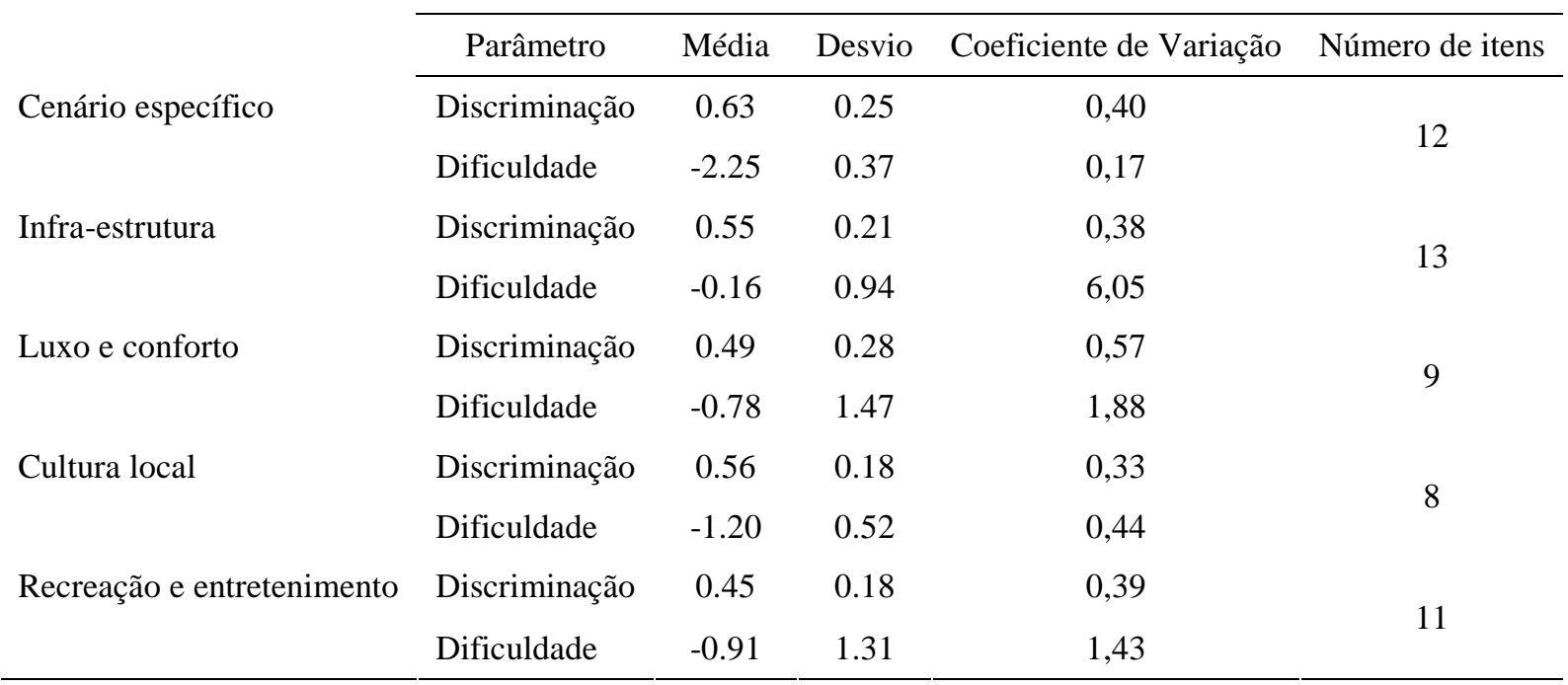

Nota. Fonte: elaborado pelos autores.

Estes resultados demonstram que a dificuldade do fator cenário específico foi muito baixa com um pequeno desvio padrão, o que aponta, portanto, que diversas pessoas endossam o que foi exposto pelos itens como fazendo parte da imagem que eles têm do Brasil. Já a discriminação deste fator foi a melhor dos 5 fatores e seu desvio adequado. Infra-estrutura apresentou a maior dificuldade, demonstrando que provavelmente os respondentes não acreditam que o Brasil possa apresentar uma adequada Infra-estrutura turística. Com relação à discriminação, este fator apresentou média e desvio aceitáveis. Luxo e conforto apresentou uma baixa média de discriminação, com o mais alto desvio padrão, sinalizando que há dificuldades com estes itens em termos de discriminação. A média de dificuldade também foi baixa. Entretanto, foi o fator que apresentou o maior desvio padrão no parâmetro de dificuldade, o que indica maior abrangência na sua configuração, o que é bastante adequado e até indicado para a construção de instrumentos psicométricos (Pasquali, 2004).

A Cultura local apresentou o segundo menor índice de dificuldade, com um desvio padrão também considerado pequeno, apontando que os respondentes endossavam que o Brasil tivesse muita manifestação cultural. A discriminação deste fator foi a segunda maior, com o menor desvio padrão, podendo ser considerado um bom fator nestes parâmetros. Finalmente, Recreação e entretenimento apresenta uma dificuldade relativamente baixa, e um desvio padrão bastante alto quando, comparado aos demais fatores, apontando que há uma amplitude de dificuldades abrangida por eles. Já para discriminação, este fator tem média relativamente baixa, contudo com um pequeno desvio, e pôde ser considerado ainda adequado. Há ausência na literatura de estudos que apontam este tipo de análise para escalas em comportamento do consumidor; assim, não é possível realizar análises comparativas entre este estudo e outros. 


\section{Análise das Médias dos Fatores e da Diferença entre os Turistas Reais e Potenciais do Brasil}

Com o objetivo de comparar a imagem que os turistas reais e potenciais têm do Brasil seguiram-se análises descritivas: a primeira buscou demonstrar qual era a imagem para cada grupo separadamente (Tabela 4); e uma comparação entre essas descritivas por meio da One-Way ANOVA. Nesta análise os dados omissos foram substituídos pela média (Tabela 5). Vale lembrar que, no presente trabalho, turistas reais são aqueles que já vieram ao Brasil, enquanto turistas potenciais são aqueles que declararam não ter vindo.

As análises abaixo foram divididas entre as pessoas que já vieram e que não vieram ao Brasil, para saber se o contato com o turismo nacional faz diferença no julgamento sobre a imagem. A Tabela 4 abaixo apresenta as medidas de tendência central e dispersão das pessoas que já tiveram contato com o Brasil e aqueles que não tiveram (turistas reais e potenciais).

Tabela 4

Respondentes que Já Vieram ao Brasil para N de Casos $=172$

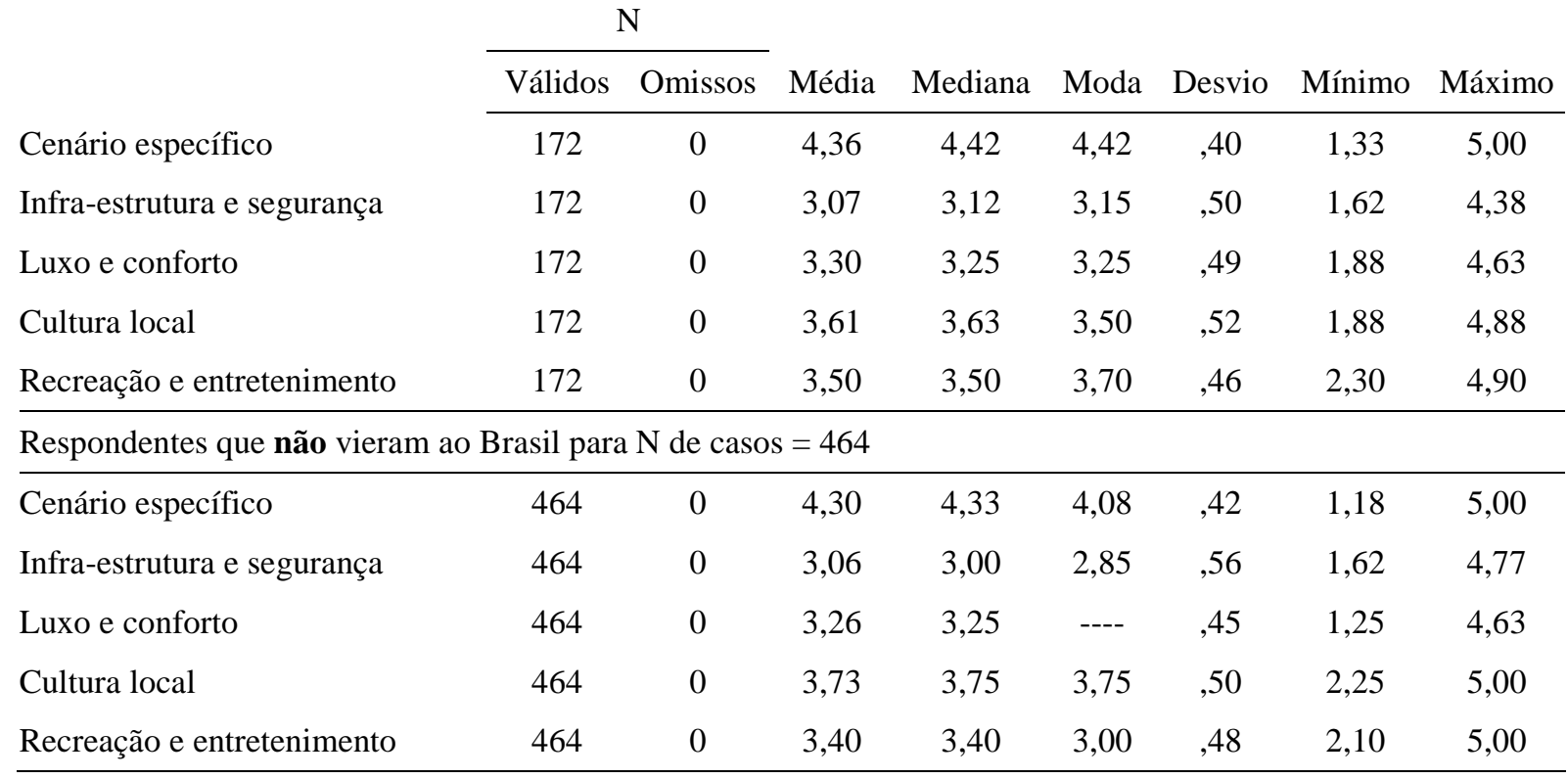

Nota. Fonte: elaborado pelos autores.

Os resultados apresentados na Tabela 4 indicam que o segundo e terceiro fator permaneceram estáveis para as duas amostras. Já o primeiro, quarto e quinto apresentaram diferenças maiores em termos da média dos escores. Ressalta-se também que os desvios padrões para esta amostra (turistas potenciais) não diferem substancialmente dos desvios da amostra anterior (turistas reais); aponta-se que as maiores diferenças estão nos fatores de Infra-estrutura e Luxo e conforto.

Procedeu-se à análise do tipo One-Way ANOVA, utilizando como variável de diferenciação os grupos de turistas reais e potenciais do Brasil. Como variável critério foram utilizados os cinco fatores encontrados nas análises. Foi possível verificar que há diferença significativa em dois dos cinco fatores no que diz respeito à Imagem que esses turistas reais ou potenciais fazem do Brasil (Tabela 5). 
Tabela 5

ANOVA entre Pessoas que Vieram e que Não Vieram ao Brasil entre os Diversos Fatores

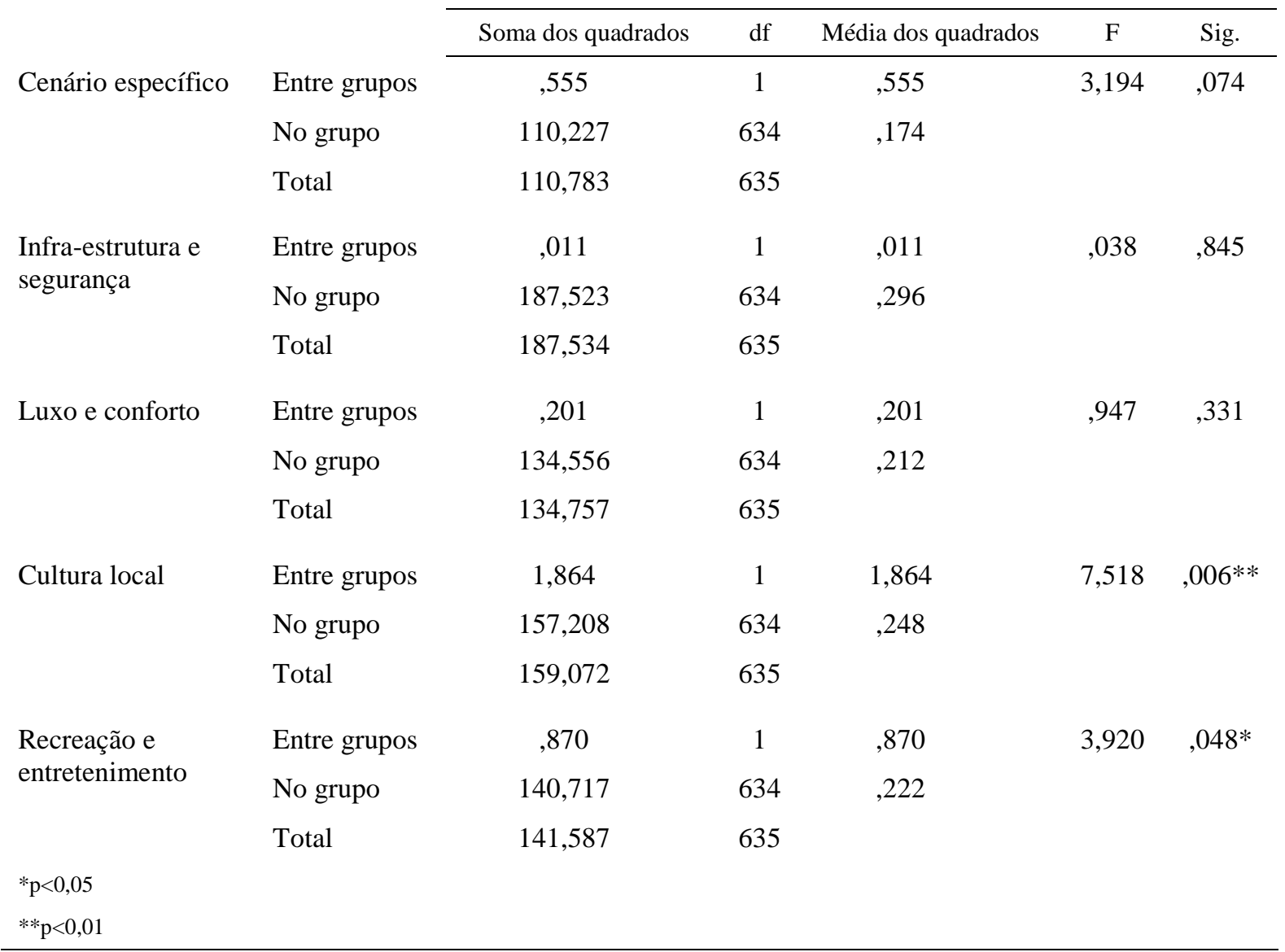

Nota. Fonte: elaborado pelos autores.

Os fatores que apresentaram diferenças significativas foram o Fator Cultura local e Recreação e entretenimento. No fator Cultura local pessoas que nunca vieram ao Brasil (turistas potenciais) esperam encontrar mais cultura do que realmente encontram (turistas reais). O fator Recreação e entretenimento apresentou o sentido inverso, ou seja, pessoas que já vieram ao Brasil apresentaram uma imagem mais favorável. $\mathrm{O}$ fator Cenário específico apresenta uma tendência à diferença, apontando que os turistas reais apresentam maiores escores que os potenciais. Os outros dois fatores não apresentam diferenças significativas entre as pessoas que tiveram contato e aquelas que não tiveram.

\section{DISCUSSÃO}

Considera-se que a pesquisa descrita neste trabalho alcançou os objetivos de construção da Escala de Medida de Imagem do Destino Brasil e de comparação entre a Imagem que turistas reais e potenciais apresentam. O fato de a visita ao Brasil modificar a imagem que se tem do país corrobora que a imagem do destino seja considerada uma atitude, conforme a definição de Fishbein e Ajzen (1975), já que indica a existência de componentes afetivo, cognitivo e conativo. 


\section{Análise do Instrumento de Imagem do Destino Turístico}

As análises dos dados demonstraram que o Instrumento de Imagem do Destino Turístico pode ser utilizado em diversas situações, tendo validade e precisão adequados, ainda que o fator referente a Luxo e conforto necessite certo aprimoramento.

A análise de Teoria de Resposta ao Item [TRI], sendo realizada com relação a apenas um objeto, é limitada. Na ausência de outros trabalhos empíricos para comparação, a presente pesquisa baseou-se apenas no objeto Brasil para sua análise, a qual não evidencia por que os itens apresentaram dificuldades altas ou baixas. Faltam comparações com outros países para apoiar adequadamente a explicação da dificuldade dos itens, ficando naturalmente como sugestão para estudos futuros e como uma das maiores contribuições do presente trabalho.

A diferença apresentada entre a percepção dos turistas reais e potenciais indica que o componente conativo, que até então não havia sido incluído na teoria de imagem do destino precisa ser levado em conta no momento da elaboração ou adaptação do instrumento. Os demais componentes da atitude, afetivo e conativo, já haviam amplamente sido testados na literatura, esta é a primeira vez que este componente está sendo descrito como parte da imagem do destino.

O fator Recreação e Entretenimento é composto pelos itens relativos a imagens específicas do lugar e sua interação com ele. Este fator foi apontado por vários autores (e.g. Leal, 2004; RezendeParker et al., 2003) e confirmado pela análise fatorial. Porém, este fator para a medida com outros países precisa ser adaptado. Ele apresentou escore mais favorável de quem já veio ao Brasil, indicando que situações específicas de interação entre o turista e o lugar são oportunidades para o desenvolvimento de uma imagem mais favorável a respeito do Brasil. É oportuno assinalar que o conteúdo desse fator pode ser mais bem aproveitado para as divulgações do Brasil no exterior.

Considerando que imagem é uma representação mental, carregada de afeto e cognição sobre um destino turístico, entende-se que tal imagem, para o turista potencial e real, é dividida em cinco fatores, sendo alguns específicos ao Brasil e outros fatores gerais que estariam presentes em todo destino turístico. Esta representação mental inclui em cada um dos fatores, de maneira não dividida, questões afetivas e cognitivas sobre aquele destino, em um mesmo fator existe um item relativo a um lugar limpo (fundamentalmente cognitivo) e um destino seguro (fundamentalmente afetivo). Portanto, afeto e cognição, como prevê a literatura de atitude (Fishbein \& Ajzen, 1975), não são separados; pelo contrário, fazem parte de cada dimensão da atitude que é direcionada a cada objeto, neste caso a cada um dos fatores.

Os fatores apresentados, portanto, são dimensões que os potenciais e reais turistas avaliam do destino turístico. Para a presente pesquisa, se pretendia desenvolver um instrumento que fosse o mais genérico e parcimonioso possível, para que, com base nas suas dimensões, fosse possível traçar paralelos e comparações posteriores com outros países. Mas, em sendo genérico, o fator Cenário Específico perdeu sua característica de descrever os cartões postais nacionais, como seria o caso de descrever a beleza do Corcovado (RJ), Pelourinho (BA), Chapada dos Guimarães (MT), Serra Gaúcha (RS) entre outras. Portanto, tornou-se passível de mensuração de outros destinos turísticos; mas perdese a especificidade local. Esta discussão levanta o questionamento da possibilidade de se medir um serviço ou produto de maneira geral. Por outro lado, se forem feitas mensurações apenas de um serviço específico, como seria possível comparar? Este fator não apresentou diferença significativa entre as médias, entretanto, uma tendência $(\mathrm{p}=0,074)$. Neste caso, o Brasil poderia trabalhar melhor seus cenários nos receptivos (turistas), já que a diferença entre uma foto e o local não estão sendo suficientemente grandes.

O fator Infra-estrutura e Segurança agregou dimensões completas, como foi o caso de comércio, logística de suporte, transporte etc. Este foi um dos fatores com menor média. Infere-se que Infraestrutura não é condição suficiente para que um turista vá visitar o país, mas, sim, apenas condição mínima necessária para que a visita ocorra, ou seja, o Brasil precisa desenvolver-se e muito neste sentido. Este dado pode indicar que é o fator que mais necessita de intervenção. O governo local e o 
nacional são essenciais ou influenciadores críticos no turismo local; portanto, são responsáveis pela maior parte da infra-estrutura básica: estradas, portos, aeroportos, ferrovias, hidrovias, comunicações, serviços de saúde, transportes urbanos etc. (Andriotis, 2002; Ruschmann, 1990).

Dos trabalhos encontrados na literatura, que tratam de imagem do destino turístico, nenhum apontou Luxo e Conforto como uma variável que fizesse parte deste construto. Assim, este instrumento apresenta uma contribuição teórica importante, pois aponta um dado ainda não apresentado. Entretanto, como este fator não era esperado na construção do instrumento, não havia itens especificamente voltados para apreender este padrão de respostas. Tal fato explica parcialmente a confiabilidade encontrada, que é ainda não ideal.

O fator Cultura Local era esperado na análise fatorial. Entretanto, esperava-se que agregasse também itens relativos a serviços culturais, e não apenas ligados a manifestações culturais e aprendizagem da cultura, como foi o caso. Vale supor que a divulgação que se faz do Brasil e a forma como ele é visto pelo turista que vem ao país apresentam grandes divergências. A valorização da cultura local e sua divulgação através de livros de história, contos, teatro, dança, filmes seriam maneiras eficazes e prazerosas de conhecer a população e seus costumes, além de preservá-los. $\mathrm{O}$ incentivo a estes eventos, em amplo espectro, é extremamente favorável para todos. No Brasil o incentivo às artes em geral ainda é incipiente, como, por exemplo, no teatro, dança, música e pintura (Corsi, 2004). Este dado indica claramente que a divulgação da cultura brasileira como algo atrativo para o estrangeiro tem sido falha, talvez porque ela não seja valorizada localmente. Neste caso, restam duas saídas: a política de comunicação mudar, no sentido de demonstrar menos sobre a cultura local, como um lugar que valoriza o típico e o diferente. Tal alternativa, porém, pode provocar a consequiência de não mais atrair esses turistas; talvez melhor seja iniciar com efetividade um apoio institucional ao folclore, teatro, dança, desde o nível mais básico.

Na presente pesquisa, parte dos itens que foram construídos tratava de captar esta imagem de turismo sexual no Brasil. Porém esta imagem não se configurou, e uma hipótese explicativa para este fato é a desejabilidade social da amostra, que pode ter sido aumentada pelo procedimento de bola de neve adotado na coleta de dados. Outra hipótese é a do viés amostral de alta escolaridade dos participantes desta pesquisa, que também reduziria o endosso desses itens.

Ainda, observou-se que o estrangeiro vê o Brasil como o brasileiro se vê e se promove. Não cabe ao estrangeiro mudar essa imagem. A questão é mais profunda que uma simples campanha publicitária no exterior, ou seja, o Brasil é limitado, mal explorado, a qualidade da mão-de-obra é mínima, o acesso é difícil, a divulgação é irrisória e carente de estruturas que o tornem competitivo para o mercado. $\mathrm{O}$ país deve definir o perfil que quer vender. Faltam verbas e incentivos para esse setor, além de uma política agressiva de mercado. Sem mudança no Brasil, não há como mudar com eficiência a imagem que se tem dele (Bignami, 2002). Por outro lado é impressionante que, com toda esta dificuldade, ele ainda se venda. De fato há algo especial no Brasil.

Pode-se afirmar o alcance de generalização nos dados encontrados, pois o perfil do turista mundial está relativamente contemplado na amostra deste estudo, assim como o nacional (Instituto Brasileiro de Turismo [Embratur], 2002; Roehl, 2001 como citado em Crocia, 2002). A pesquisa também demonstrou que é possível a construção de um instrumento válido e preciso de imagem, que pouco foi encontrado na literatura. Há também uma lacuna de estudos que objetivem o médio e longo prazo e que procurem manter uma série histórica, útil para monitoramento de agências reguladoras e outros órgãos. Logrou-se com que ocorresse a integração da técnica da psicologia ao marketing (i.e., psicometria e psicologia social ao conceito de imagem).

\section{Limitações}

Este trabalho coletou dados via Internet, em ambiente aberto, viabilizando a entrada de qualquer tipo de pessoa em seu domínio, sem controle. Isto pode ter gerado distorções nos dados. Além disso, a 
coleta limitou-se a apenas a quatro idiomas (inglês, francês, espanhol e português), o que também é grande limitador; haja vista que nenhum idioma oriental foi utilizado na coleta de dados.

Este trabalho teve também a limitação de utilizar apenas um método para ter acesso à imagem que o estrangeiro tem do destino turístico Brasil. Para uma próxima pesquisa indica-se também este tipo de dado para complementar e confrontar os resultados obtidos aqui. Além disso, como a coleta foi integralmente realizada pela Internet, não foi possível ser representativo para aquela população que não a utiliza.

\section{Agenda Futura}

O primeiro tópico a ser mencionado é sobre o aperfeiçoamento da dimensão e do fator relativo a luxo e conforto. Para futuras pesquisas, como se indica no trabalho de Pérez-Nebra e Torres (2002a), seria interessante conhecer qual é a importância de cada um dos atributos da escala que o turista dá no momento de sua decisão de um destino turístico e finalmente saber qual sua satisfação no momento em que ele sai do país. Desta maneira seria possível ter um corte em três momentos: (1) Processo de decisão (imagem), (2) Processo de compra (importância dos atributos) e (3) avaliação pós-consumo (satisfação).

Seria interessante incluir nos próximos trabalhos variáveis para mensuração e segmentação cultural, baseando-se na afirmação de Rokeach (1973) de que o conhecimento dos valores do indivíduo pode possibilitar boa predição de seus comportamentos e atitudes. Paralela a esta agenda, também seria interessante confirmar se as dimensões aqui encontradas seriam universais para outros países; neste sentido, se seriam generalizáveis ao conceito de imagem do destino. Para isso deveriam ser construídos outros instrumentos e validados com o mesmo referencial psicométrico.

\section{Artigo recebido em 15.09.2007. Aprovado em 20.08.2008.}

\section{AGRADECIMENTOS}

Os autores deste trabalho gostariam de agradecer aos pareceristas os seus comentários, especialmente em relação a comparação entre países, que muito enriqueceram a elaboração deste trabalho.

\section{REFERÊNCIAS BIBLIOGRÁFICAS}

Alexander, M. G., Brewer, M. B., \& Livingston, R. W. (2005). Putting stereotype content in context: image theory and interethnic stereotypes. Personality and Social Psychology Bulletin, 31(6), 781-794.

Allen, M. W. (1997). The direct and indirect influences of human values on consumer choices. Tese de doutorado não-publicada, Victoria University of Wellington, Wellington, Nova Zelândia.

Amend, M., Silva, J. C. G. L., Niefer, I. A., \& Martins, G. (2002). A utilização da análise fatorial para a determinação das características do mercado econturístico. Turismo: Visão e Ação, 4(10), 27-41.

Andriotis, K. (2002). Residents' satisfaction or dissatisfaction with public sector governance: the Cretan case. Tourism and Hospitality Research, 4(1), 53-68.

Ansarah, M. G. R. (2002). Turismo: segmentação de mercado [Introdução]. São Paulo: Editora Futura. 
Barretto, M. (2000). As ciências sociais aplicadas ao turismo. In C. Serrano, H. T. Bruhns, \& M. T. D. P. Luchiari (Orgs.). Olhares contemporâneos sobre o turismo (pp. 17-36). Campinas: Papirus.

Beni, M. C. (2001). Análise estrutural do turismo (6a ed.). São Paulo: Senac.

Bignami, R. (2002). A imagem do brasil no turismo. São Paulo: Editora Aleph.

Brislin, R. W. (1980). Translation and content analysis of oral and written materials. In H. C. Triandis \& J. W. Berry (Eds.). Handbook of cross-cultural psychology (Vol. 4, pp. 398-444). Boston: Allyn \& Bacon.

Brislin, R. W., Lonner, W., \& Thorndike, R. M. (1973). Cross-cultural research methods. New York: Wiley.

Corsi, E. (2004). Patrimônios histórico-culturais: uma nova perspectiva para o urbano e o rural através do turismo sustentável. Caminhos de Geografia, 2(10), 22-34.

Crocia, N. (2002). Análse regional e destinações turísticas: possibilidades teóricas e situações empíricas em geografia do turismo. Turismo: Visão e Ação, 4(11), 9-32.

Crompton, J. L. (1979). An assessment of the image of Mexico as a vacation destination and the influence of geographical location upon that image. Journal of Travel Research, 17(4), 18-23.

Day, J., Skidmore, S., \& Koller, T. (2002). Image selection in destination positioning: a new approach. Journal of Vacation Marketing, 8(2), 177-186.

Echtner, C. M., \& Ritchie, J. R. B. (1991). The meaning and measurement of destination image. The Journal of tourism Studies, 2(2), 2-12.

Fishbein, M., \& Ajzen, I. (1975). Belief, attitude, intention and behavior: an introduction to theory and research. USA: Addison-Wesley Publishing Company.

Hunt, J. D. (1975). Image as a factor in tourism development. Journal of Travel Research, 13(3), 1-7.

Instituto Brasileiro de Geografia e Estatística. (2007). Pesquisa mensal de emprego. Recuperado em $27 \quad$ agosto, 2007, de http://www.ibge.gov.br/home/estatistica/indicadores/trabalhoerendimento/pme_nova/defaulttab _hist.shtm

Instituto Brasileiro de Turismo. (2002). Anuário estatístico (Vol. 29). Brasília: autor.

Jacoby, J., Hoyer, W., \& Brief, A. (1992). Consumer psychology. In M. D. Dunnette \& L. M. Hough (Orgs.). Handbook of industrail and organizational psychology (Vol. 3, pp. 377-441). California: Consulting Psychologists.

Joppe, M., Martin, D. W., \& Waalen, J. (2001) Toronto's image as a destination: a comparative importance-satisfaction analysis by origin of visitor. Journal of Travel Research, 39(3), 252-260.

Kahle, K. R. (1995). Social values and consumer behavior: research from the list of values. In C. Seligman, J. M. Olson, \& M. P. Zana (Eds.). The psychology of values: the Ontario Symposium, (Vol. 8, pp. 135-151). Mahwah: Lawrence Erlbaum.

Laverie, D. A., \& Murphy, P. E. (1993). The marketing and public policy literature: a look at the past ten years. Journal of Public Policy \& Marketing, 12(2), 258-267.

Leal, S. (2002). A relevância da imagem para o processo de escolha de destinações. Revista Eletrônica de Turismo, 1(2), 1-6. 
Leal, S. (2004). A imagem de destinações turísticas: um estudo de caso do Brasil na percepção de alunos baseados na Austrália. Retur, 2(2), 1-8.

Leisen, B. (2001). Image segmentation: the case of a tourism destination. The Journal of Services Marketing, 15(1), 49-66.

Mariani, M. A. P. (2002). Percepção dos turistas e moradores do município de Bonito: o lugar, os sujeitos e o turismo. Turismo: Visão e Ação, 4(11), 33-46.

Muraki, E., \& Bock, R. D. (1997). PARSCALE IRT Item analysis and test scoring for rating-scale data. Chicago: Scientific Software International.

Organização Mundial de Turismo. (1999). Turismo panorama 2020: nuevas previsiones de la OMT. Avance actualizado. Madrid: Autor.

Organização Mundial de Turismo. (2000). Relatório Anual. Madrid: Autor.

Organização Mundial de Turismo. (2001). Introdução ao turismo (D. M. R. Corner, Trad.). São Paulo: Roca. (Obra Original publicada em 1998).

Organização Mundial de Turismo. (2003). Relatório Anual. Recuperado em 13 janeiro, 2003, de http://www.world-tourism.org/statistics/tsa_project/basic_references/castellano/X.3.htm

Paiva, M. G. M. V. (1995). Sociologia do turismo. Campinas: Papirus.

Pasquali, L. (1999). Instrumentos psicológicos: manual prático de elaboração. Brasília: LabPAM; IBAPP.

Pasquali, L. (2004). Psicometria: teoria dos testes na psicologia e na educação. Petrópolis: Vozes.

Pasquali, L. (2006). Análise fatorial. Brasília: LabPAM.

Pérez-Nebra, A. R., \& Torres, C. V. (2002b, outubro). Construção e validação da escala de satisfação do consumidor estrangeiro sobre a indústria de turismo brasileiro. Anais da Reunião Anual da Sociedade Brasileira de Psicologia, Florianópolis, SC, Brasil, 32.

Pérez-Nebra, A. R., \& Torres, C. V. (2002a). Imagem do Brasil como país de destino turístico: uma pesquisa da psicologia do consumidor. Turismo: Visão e Ação, 4(10), 101-114.

Petrocchi, M. (2001). Gestão de pólos turísticos. São Paulo: Futura.

Rezende-Parker, A. M., Morrison, A. M., \& Ismail, J. A. (2003). Dazed and confused? An exploratory study of the image of Brazil as a travel destination. Journal of Vacation Marketin, 9(3) 243-259.

Rodrigues, A., Assmar, E. M. L., \& Jablonski, B. (1999). Psicologia social (18a ed.). Petrópolis: Vozes.

Rokeach, M. (1973). The nature of human value. New York: Free Press.

Ruschmann, D. (1990). Marketing turístico. Campinas: Papirus.

Simonson, I., Carmon, Z., Dhar, R., Drolet, A., \& Nowlis, S. M. (2001). Consumer research: in search of identity. Annual Review of Psychology, 52, 249-275.

Spotts, D. M., Kim, D. K., Carr J. M., \& Holecek, D. F. (1998, June). An analysis of michigan's image as a tourist destination. Proceedings of the Annual Conference of the Travel and Tourism Research Association, Fort Worth, TX, USA, 29.

Swarbrooke, J., \& Horner, S. (2002). O comportamento do consumidor no turismo. São Paulo: Aleph. 
Trigo, L. G. G. (2000). Turismo básico. São Paulo: Senac.

Wirtz, J., \& Bateson, J. E. G. (1995). An experimental investigation of halo effects in satisfaction measures of service attributes. International Journal of Service Industry Management, 6(3), 84-102. 